\title{
创新编研工作思路 提亮档案编研成果
}

\section{Creativing Editing and Research Ideas to Highlight the Results of Archival Editing and Research}

\section{王海雷}

Hailei Wang

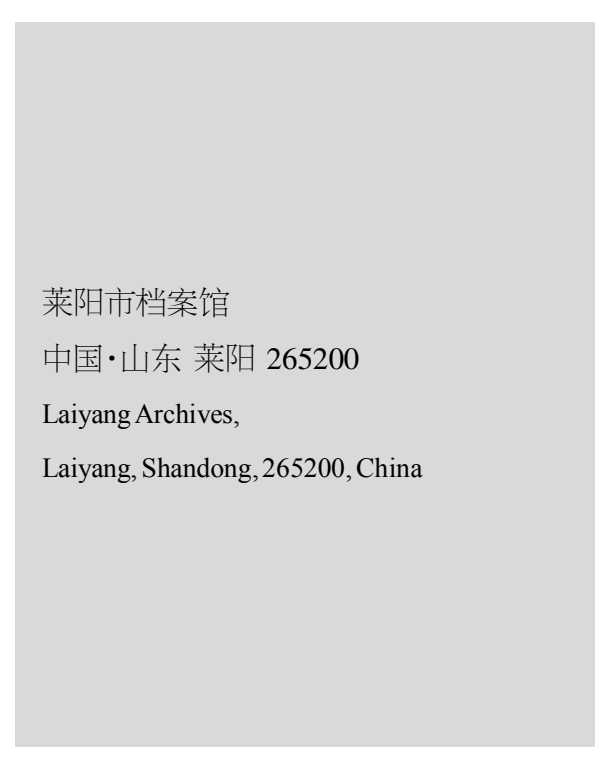

\section{1 档案编研工作实践}

\section{1 从发掘资源入手, 丰富档案编研内容}

档案部门在编研实践中, 针对重大活动、特色档案等资源 加大征集力度, 建立“红色基因文化”“优秀历史文化”等主题 的档案编研资源库, 在此基础上积极开展档案编研工作。例 如, 莱阳市档案馆全程指导胶东地委《胶东红色印记莱阳红色 文化丛书》的编纂工作; 再如, 档案部门充分利用馆藏档案资 源, 编辑出版了《中国共产党山东省莱阳市组织史资料》 （1998.6-2008.6)等多种编研成果, 对推进社会主义核心价值 体系建设、传播文化正能量、弘扬社会主义先进文化具有重要 的现实意义。

\section{2 拓展多方合作,创新档案编研模式}

确立“丰富内涵、扩展外延”为莱阳档案文化建设总目标, 加强横向联系, 在档案编研模式上进行积极创新, 与专业研究 机构、民间档案文化爱好者合作。例如, 莱阳市档案馆与螳螂 拳协会合作编撰了《螳螄拳》, 填补了莱阳市武术学术研究方 面的空白, 成为全市首部记录地方性武术的史料性专著, 为传 承地方文化留下了宝贵的历史资料; 莱阳市档案馆与民间档 案文化爱好者合作, 相继推出了《五龙鹅》《莱阳芋头》《莱阳 梨》等“一百个”系列编研成果, 在社会上引起了较大反响, 受 到社会各界的好评。

\section{3 借助科技引领, 拓展档案编研领域}

充分借助现代信息技术的优势, 将多媒体引入编研领域, 不断提升编研成果的生动性和形象性, 形成了一批文献纪录 片、电子图书等形式多样、观赏性强的档案编研成果 ${ }^{[1]}$ 。莱阳 市档案馆在馆内设置滚动显示屏, 推出新媒体系列栏目, 以改 革开放以来的珍贵档案为素材, 通过专题纪录片, 展现莱阳的 发展成就,给公众以耳:目一新、形象直观的多维体验。

\section{2 档案编研对当前工作的新要求}

\section{1 做好档案编研工作, 需要转变传统的保守观念}

档案人员应充分认识到保存档案的最终目的一档案的 利用, 要转变重保管、轻利用的保守观念, 通过各种方式把“死 档案”变为 “活资料” ${ }^{[2]}$ 。大多数档案工作者的工作重心放在常 规性工作上,对档案编研工作关注不够。档案人员要勇于走向 前台, 紧跟时代步伐, 紧紧围绕中心工作和社会热点问题, 积 极主动地进行档案资料的编研。要敢于展示档案机构的自身 价值和档案人员的风采, 突出编研特色, 不断地引导和强化社 会大众对档案工作的正向认识。

\section{2 做好档案编研工作,需要夯实档案基础工作}

一是库藏档案要丰富多样, 满足多方需求。编研工作需要 大量资料的支撑, 要求库藏档案既要有党政重要档案, 也要有 社会民生特色的档案资料, 还要有奖牌、锦旗等实物载体的档 
图书馆管理 Library Management

案资料, 保管材质上既要有传统纸质档案, 也要有电子档案。 档案的收集工作工作量大，需要档案人员注意开拓各种收集 渠道, 发挥各种主动性。二是要重视档案利用统计和信息反馈 工作。档案部门要做好档案利用实例汇编, 让人们充分认识到 档案利用信息反馈的重要性。

\section{3 做好档案编研工作,需要不断提高档案人员} 的综合素质

一是要注重专业知识的学习。在日常工作中, 档案编研工 作人员要加强档案专业理论知识的学习，同时针对本馆藏档 案所需要的学科知识进行补短和加强, 要营造团结合作、积极 进取的工作氛围, 培养一专多能的档案工作技能。二是要培养 档案人员的创新意识。要改变传统的手工加工处理档案信息 的方法, 善于借助各种先进处理技术, 并运用现代多媒体技术 对传统档案进行再加工, 提高编研工作效率和编研质量。

\section{3 当前档案编研工作存在的问题及原因} 分析

\section{1 编研成果缺乏亮点作品}

部分档案编研成果多以反映工作情况为主，或侧重于文 件汇编、大事记编写等基础性工作, 缺乏对档案资料的深入加 工, 不能形成研究成果, “编” “研”脱节的现象比较严重, 多为 资料编纂, 档案编研学术价值较低。

\section{2 编研成果与现实服务脱节}

编研工作选题思路不宽, 思维模式较为传统陈旧, 立足点 为馆藏档案, 以传统思路为主, 不能与时俱进、以服务为导向 进行编研。编研工作对群众关心的热点问题不够敏感,在为党 委政府中心工作服务方面也缺乏主动性。

上述问题的主要原因, 可归为以下三个方面:一是缺乏专 业人员。档案部门大部分工作人员按照公务员序列进行管理, 缺乏专业人员的补充, 大多数工作人员是边干边学, 没有经过 专业培训, 对档案编研知识和档案专业技术的了解程度不深。 二是缺乏专职人员。由于档案部门工作人员往往身兼多项职 责,不仅负责档案的征集接收、保管利用、安全管理,在专业工 作之外还要承担大量的行政事务性工作，没有多余时间和精 力用于档案编研工作。三是缺乏专门资源。档案编研需要有丰 富的馆藏档案资源,但不少档案馆馆藏档案门类不多、结构单 一, 工作人员只能 “就米下锅”, 受制于档案资料, 不能顺畅开 展档案编研的选题工作, 难以有效进行档案编研。

\section{4 创新档案编研工作的思考建议}

\section{1 加强合作, 实现多部门联合编研}

打破档案部门传统的编研思路, 积极寻求档案部门之间、
与非档案部门、与社会各界的合作。在选题方面, 不仅要立足 馆藏档案, 还要积极与其他行业如信息、科技、经济部门及图 书馆、博物馆、新闻单位等开展合作编研, 拓宽选题范围, 扩大 材料来源。

\section{2 探索建立专题数据库, 强化工具支撑}

在档案馆藏数据库的基础上探索建立二级数据库一一编 研专题数据库, 分层次、分类别地进行有序建库。在数据库层 次方面, 先建立选题目录数据库, 后建立选题内容数据库。前 者建库时可参考档案目录数据库建库的一般方法, 后者依据 档案编研选题的一般流程进行建设。通过专题数据库负责对 实体信息的分析、过滤、加工, 既可为利用者的检索提供方便, 也是史料研究的抓手。

\section{3 丰富档案编研内容, 强化档案编研与开发利}

\section{用工作的服务质量}

一是档案馆扩大合作学习,建立统一的交流平台, 促进信 息共享和学习,形成多元化的新兴合作模式,保证档案的选题 互动化。二是档案编研工作涉及编纂档案史料和文件汇编、专 题参考资料编写、档案和历史研究三个主要内容, 应当以社会 经济发展和政府行政决策服务为前提，以面向社会群体的服 务为导向。

\section{4 实现编研成果的特色化}

档案馆应树立“管用并举, 重在利用”和“重特色, 争一流” 的工作思路, 充分挖掘档案文化资源, 围绕党政中心工作、重 大节庆、地方文化三个中心, 深入实施档案编研特色建设工 程, 推出主动服务中心工作,切实体现地域特点的档案文化精 品成果。

\section{5 结语}

档案编研工作是一项长期工作, 是档案价值的重要体现。 把传统工作做出新成果、新特色、新亮点,合理、高效地利用档 案材料, 编研档案成果, 满足社会各界对档案的服务需求, 是 相关人员努力的方向。档案部门工作人员要在夯实基础工作 的基础上不断提升档案编研工作高度, 以编研成果展示档案 价值, 扩大档案工作影响, 取得社会各界对档案部门的关心和 支持,促进整个档案事业的繁荣发展。

\section{参考文献}

[1]王晓璐.从公众档案文化需求视角论档案编研工作出路 [J].浙 江档案,2011(5):32-35.

[2]严永官.档案编研理论的继承与发展 [J].中国档案,2001(3): 45-47. 